\title{
HYPER-HYDROPHILIC TITANIUM SURFACES IMPROVE OSTEOBLAST ATTACHMENT BY ENHANCING FIBRONECTIN ADSORPTION AT THE INTERFACE
}

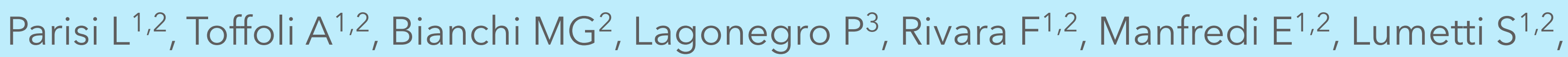 \\ Galli $C^{1,2,3}$, Macaluso GM1,2,3
}

BACKGROUND: Implants osseointegration is affected by cell responses at the bone-implant interface, which depends on the chemical composition, micro-topography and WETTABILITY of the surface, which, in turn, influence PROTEIN ADSORPTION.

AIM: To investigate wheter hyper-hydrophilicity alters surface selectivity for FIBRONECTIN, a protein which plays a pivotal role in CELL ADHESION and PROLIFERATION.

MATERIALS \& METHODS: Acid-etched sandblasted surfaces were treated through a proprietary process in order to obtain hyper-hydrophilic surfaces. Surface features were characterized by X-Ray Photoelectron Spectroscopy (XPS), Scanning Electron Microscopy (SEM), and the measurement of the contact angle. Protein adsorption was assessed by SDS-PAGE analysis, and the influence of surface in fibronectin adsorption was assayed through Western Blot. Cell attachment to the surfaces was then studied. Murine osteoblasts MC3T3-E1 cells were cultured for 24h in complete medium. Their morphology and adhesion were studied through the immune-staining for cytoskeleton and for focal adhesions and through the use of SEM microscopy coupled to Focused lon Beam (FIB). FIB analysis allowed to cut cells during SEM observation and to investigate their interactions with the surface. Furthermore, cell adhesion was assessed by quantitating the amount of attached cells to the surface at different experimental points through a chemiluminescence assay.

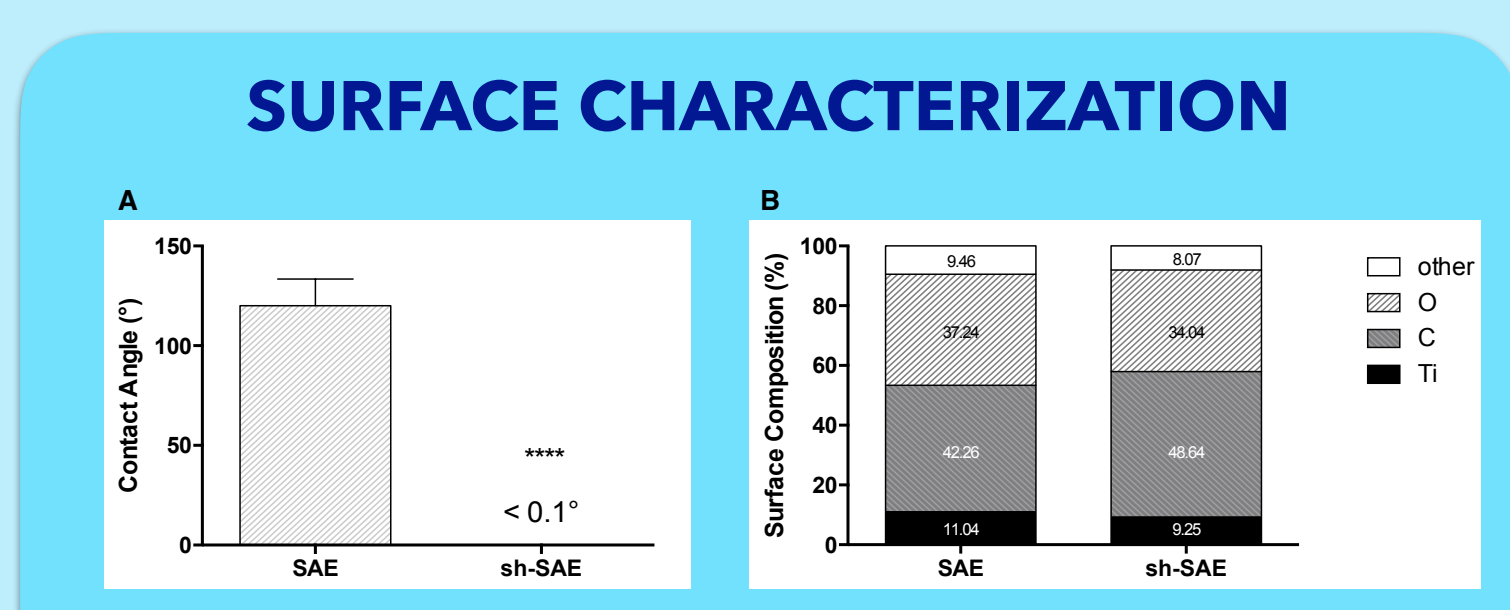

Figure 1: (A) Histograms representing contact angle between titanium surface and a $5 \mu l$ water droplet. $(B)$ Histograms representing atomic percentage of the chemical species present in the sample and studied through X-Ray Photoelectron Spectroscopy (XPS).

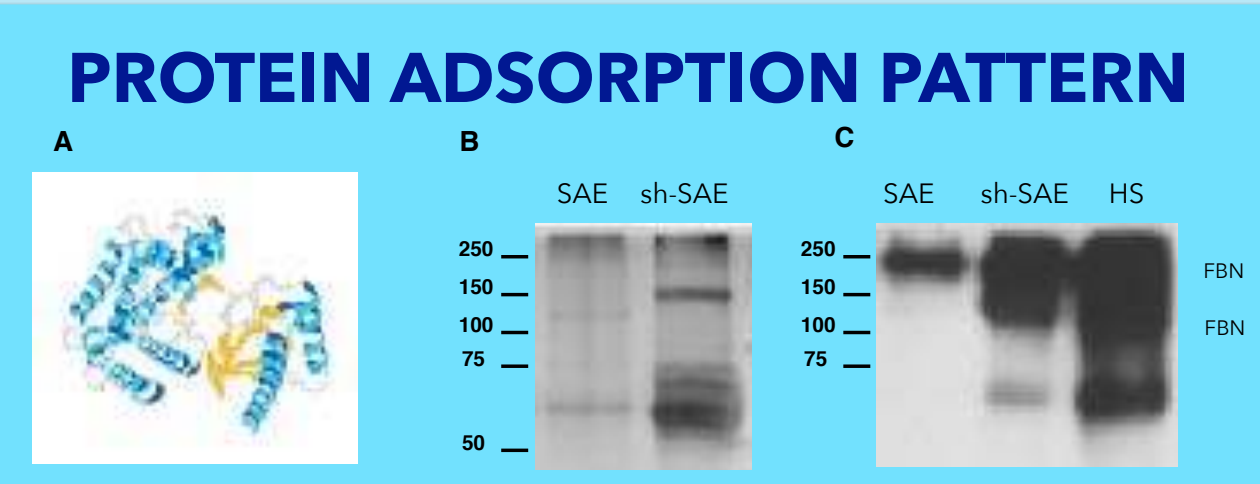

Figure 2: (A) Structure of human plasma fibronectin (source: http://www. sigmaaldrich.com/catalog/ product $/ \mathrm{mm} / 341635) 10 \%$ SDS-PAGE separation of blood plasma proteins adsorbed on SAE and sh-SAE titanium discs stained with Silver Stain. (C) Western Blot analysis of fibronectin adsorption on SAE and sh$S A E$ discs, compared to human serum (HS) fibronectin.

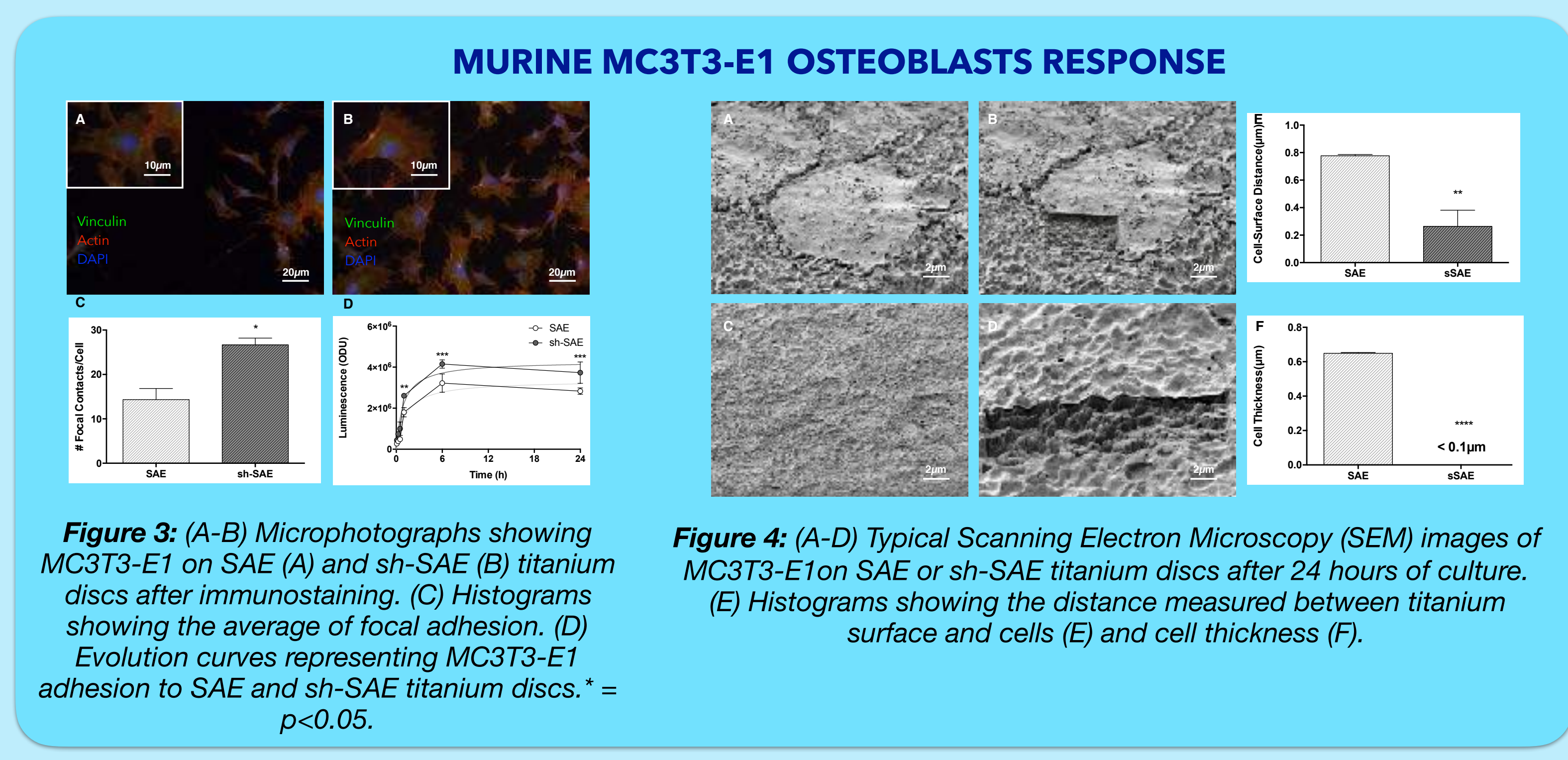

CONCLUSIONS: Taken together our data show that HYPER-HYDROPHILICITY AFFECTS PROTEIN ADSORPTION. In particular, we observed a more selective adsorption of FIBRONECTIN, which may be responsible for IMPROVED CELL ADHESION to micro-patterned titanium. 